\title{
Dexmedetomidine attenuates the toxicity of $\beta$-amyloid on neurons and astrocytes by increasing BDNF production under the regulation of $\mathrm{HDAC2}$ and $\mathrm{HDAC5}$
}

\author{
YUELING WANG $^{1 *}$, AIJUN JIA ${ }^{2 *}$ and WENJUAN MA ${ }^{1}$ \\ ${ }^{1}$ Department of Anesthesiology, Xiangya Hospital, Central South University, Changsha, Hunan 410008; \\ ${ }^{2}$ Department of Respiratory Medicine and Intensive Care Unit, The Affiliated Hospital \\ of Guilin Medical University, Guilin, Guangxi 541000, P.R. China
}

Received February 5, 2018; Accepted June 6, 2018

DOI: $10.3892 / \mathrm{mmr} .2018 .9694$

\begin{abstract}
Cytotoxicity of $\beta$-Amyloid $(A \beta)$ is a major contributor to the pathogenesis of Alzheimer's disease. Dexmedetomidine (Dex) has been revealed to have multiple neuroprotective actions as a clinical anesthetic agent. The aim of the present study was to investigate the protection of Dex against $A \beta$ in neurons and astrocytes, and the possible protective mechanisms. Primary neurons and astrocytes were isolated respectively from the hippocampus and cerebral cortex of neonatal Sprague Dawley rats. The neurons and astrocytes were incubated with $A \beta$ in the presence or absence of Dex, which was followed by evaluation of the cell viability and apoptosis. Reverse transcription-quantitative polymerase chain reaction, western blotting and ELISA assays were performed to assess the levels of specific genes or proteins. The results revealed that $A \beta$ decreased the viabilities of neurons and astrocytes in a dose-dependent manner, and elevated the rate of apoptosis. However, Dex attenuated the detrimental effects of $\mathrm{A} \beta$. $\mathrm{A} \beta$ caused deacetylation of histone $\mathrm{H} 3$ by promoting the accumulation of histone deacetylase (HDAC)- 2 and HDAC5 in the cell nucleus, resulting in the reduced production of brain-derived neurotrophic factor (BDNF). However, Dex reversed the $A \beta$-induced deacetylation of histone $\mathrm{H} 3$ and thus, increased BDNF production. Using a HDAC inhibitor or recombinant BDNF protein also protected the neurons and astrocytes against $A \beta$ cytotoxicity. These results suggested that the protective effect of Dex against $A \beta$ is particularly relevant to BDNF. Thus, the present study provides a foundation for the
\end{abstract}

Correspondence to: Professor Wenjuan Ma, Department of Anesthesiology, Xiangya Hospital, Central South University, 87 Xiangya Road, Changsha, Hunan 410008, P.R. China

E-mail: mwj_mary@hotmail.com

*Contributed equally

Key words: $\beta$-amyloid, dexmedetomidine, brain-derived neurotrophic factor, histone deacetylase 2 , histone deacetylase 5 further study of Dex protection against $A \beta$ in animal models and pre-clinical researches.

\section{Introduction}

Alzheimer's disease (AD) is a neurodegenerative disease which is incurable with higher occurrence in elder people (1). With ever-increasing elder populations in both developed and developing countries, AD has become a huge public health problem and asocial and economic burden. AD patients usually have neurological deficits including the loss of memory and other cognitive abilities and a change in their personality (2). Histopathologically, AD is characterized by the presence of senile plaques in the extracellular medium, intracellular inclusions of neurofibrillary tangles (NFT) and loss of neurons. Amyloid $\beta(\mathrm{A} \beta)$ is a major component of senile plaques. It is widely accepted that the accumulation of $A \beta$ is essential for $\mathrm{AD}$ pathogenesis (3). $\mathrm{A} \beta$ is associated with neuronal cell death, NFT formation, inflammation and oxidative damage in AD (3). $\mathrm{A} \beta$-induced neurotoxicity inhibits hippocampal neurogenesis and synaptic plasticity, resulting in brain dysfunction in cognition, learning and memory (1). Therefore, $A \beta$ is proposed as the most important causative factor of AD. Numerous studies have been performed to inhibit the formation of $\mathrm{Ab}$ and to attenuate its toxicity.

Neurotrophic factors, together with essential proteins secreted by neurons and glial cells, support neuronal survival, proliferation and maturation as well as maintain the homeostasis of peripheral and central nervous system (4). Brain-derived neurotrophic factor (BDNF) is a major central neurotrophic factor in the central nervous system (4). Reduction of BDNF was reported in the brains of cognitive impairment patients, including AD patients $(5,6)$. As BDNF involves in neuronal survival and neuronal functions, it is proposed that the reduction of BDNF is associated with the pathogenesis of $\mathrm{AD}$ (4). Studies performed in vitro and in vivo suggested that BDNF inhibited A $\beta$-induced neurotoxicity (7-9).

The reduction of BDNF in the brains of $\mathrm{AD}$ patients is possibly due to the epigenetic modulations. Epigenetic modulations refer to the regulation of gene expression by manipulating DNA-related proteins rather than DNA, including acetylation, 
methylation, phosphorylation, ubiquitinylation, carbonylation and glycosylation. Epigenetic modulations commonly occur at histones, remodeling chromatin between relatively 'open' and 'closed' forms (10). Significant decreased acetylation of histone was reported in both $\mathrm{AD}$ transgenic mice and postmortem human brains (11). The level of histone acetylation is regulated by acetyltransferase and histone deacetylase (HDAC). An increase of HDAC2 was observed in the hippocampus of AD patients (12). The electrostatic interaction between positively charged histones and negatively charged DNA leads to a condensed and repressive chromatin structure $(10,11)$. The acetylation of histones attenuates their positive charges, resulting in a reduced affinity of histones to DNA and a free chromatin for recruiting transcription factors to genes $(10,11)$. HDACs can remove acetyl groups from histones, which conversely produces a condensed chromatin structure and repressed gene expressions (13). A $\beta$ induces epigenetic changes by promoting HDAC2 expression, resulting in BDNF reduction (14). In AD transgenic mouse models, cortical expression of BDNF and BDNF-mediated TrkB retrograde trafficking are inhibited when neuronal culture submitted to $A \beta$ peptides (2).

The traditional anesthesia (e.g., isoflurane-mediated anesthesia) increases the risk of AD (15-17). Some traditional anesthetic agents are associated with AD pathogenesis (18). Behavioral tests in rodent models showed that a transient exposure to anesthetic drug isoflurane caused a lasting impairment to the cognition $(15,16,19)$. A cell co-cultured study showed that isoflurane interfered astrocytes to support neuronal growth, which may explain the association between the anesthesia application and AD pathogenesis (20). Dexmedetomidine (Dex), a specific agonist of $\alpha 2$-adrenoceptor, has been used as a new type of clinical anesthetic agent. Dex recently attracts numerous attentions because of its multiple neuroprotective actions in experimental and pre-clinical studies $(21,22)$. Additionally, Dex has been found to inhibit the postoperative cognitive dysfunction induced by isoflurane, which indicates the potential protection of Dex against cognitive function impairment and even AD (23). The mechanisms underlying neuroprotective actions remain largely undefined, however, a study of the protective effect of Dex against septic acute kidney injury revealed an important molecular basis that Dex blocked the transport of HDAC2 and HDAC5 to nuclear and inhibited the acetylation of histone $\mathrm{H} 3$ (24).

Therefore, we hypothesized that Dex increases BDNF production by manipulating HDAC2 and HDAC5 and consequently attenuate $\mathrm{A} \beta$ cytotoxicity. BDNF is mainly produced by neurons and astrocytes. This study prepared primary neurons and astrocytes and further investigated our hypothesis on these cells.

\section{Materials and methods}

Ethics statement. The present study was approved by the Ethics Committee of Xiangya School of Medicine (Hunan, China).

Preparation of primary neurons and astrocytes. Primary neurons and astrocytes were acquired from 1-2 days' neonatal Sprague Dawley rats according to a previous protocol (25). Eight Rat pups (1-2 days; Central South University, Changsha, China) were housed in vivariums that was maintained at fixed temperature $\left(22-23^{\circ} \mathrm{C}\right)$ and moisture $(70 \%)$, with a 12 -hour light on/off cycle. They sucked milk from the maternal rat. All procedures were adhered to National Institutes of Health Guidelines for the care and use of animals (26). Rat pups were euthanatized, immersed in $75 \%$ alcohol for $5 \mathrm{~min}$, and then washed with D-Hank's. The brain of neonatal rats was removed in a sterile field. The cerebral cortex and hippocampus were isolated on ice for the preparation of primary astrocytes and neurons, respectively. After removing meninges and blood vessels, the cerebral cortex and hippocampus were cut into a cubic millimeter pieces and digested by $2 \mathrm{mg} / \mathrm{ml}$ papain and $0.05 \mathrm{mg} / \mathrm{ml}$ DNAase in serum-free medium at $37^{\circ} \mathrm{C}$ for $30 \mathrm{~min}$. The tissue suspension was gently pipetted to disperse the cells and filtered through $100 \mu \mathrm{M}$ sterile filter. Neocortical cells were plated in dishes at a density of $4 \times 10^{5}$ cells $/ \mathrm{ml}$ in Dulbecco's modified Eagle medium with $10 \%$ fetal bovine serum (FBS; both Hyclone Laboratories Inc., Logan, Utah, USA), epidermal growth factor $(10 \mathrm{ng} / \mathrm{ml})$, penicillin $(50 \mathrm{U} / \mathrm{ml})$, and streptomycin (50 U/ml; all Sigma-Aldrich; Merck KGaA, Darmstadt, Germany). When astrocytes reached confluence, microglia were removed by shaking at $200 \mathrm{rpm}$ for at least $24 \mathrm{~h}$. Relatively pure neuronal cultures from hippocampus tissues were infused into a poly-lysine-treated plate. After $4 \mathrm{~h}$ cultivation, the medium was removed and new neurobasal-A medium with B27 (1\%), glutamine $(0.5 \mathrm{mmol} / \mathrm{l})$, penicillin $(50 \mathrm{U} / \mathrm{ml})$, streptomycin $(50 \mathrm{U} / \mathrm{ml})$ and cytosine arabinoside (3 $\mu \mathrm{M}$; all Sigma-Aldrich; Merck KGaA) was added in the plate. The cytosine arabinoside was added to inhibit glial proliferation, but cytosine arabinoside was removed from the media before cells were treated with $\mathrm{A} \beta$ and Dex to eliminate the interference. The neurons and astrocytes were initially cultured for 2 days (passage 0, day 2; P0D2) and subcultured for 4 days (passage 1, day 4; P1D4). Neurons and astrocytes at the second passage (P2D4) were used for further study.

Immunocytochemistry (ICC). Neurons and astrocytes in the cultures were identified using ICC. Neurons and astrocytes were fixed in $4 \%$ paraformaldehyde for $15 \mathrm{~min}$, permeabilized and blocked in $0.1 \%$ Triton X-100 with 5\% normal goat serum (Sigma-Aldrich; Merck KGaA) in phosphate-buffered saline (PBS) for $30 \mathrm{~min}$ at room temperature. Neurons and astrocytes were then incubated with primary antibodies against $\beta$-Tubulin III (1:200; T2200) and glial fibrillary acidic protein (GFAP; 1:400 dilution; HPA056030; both Sigma-Aldrich) for 1-4 $\mathrm{h}$ at room temperature, respectively. Samples were washed three times in PBS, followed by the incubation in horseradish peroxidase (HRP)-labeled anti-IgG secondary antibody $(1: 2,000)$ for $1 \mathrm{~h}$ and DAB (both Sigma-Aldrich; Merck KGaA) for $3 \mathrm{~min}$ at room temperature. After additional washes, samples were stained using hematoxylin and imaged using a microscope (Axio Imager 2; Zeiss AG, Oberkochen, Germany).

Cell treatments. Monomeric Amyloid $\beta$-protein (A $\beta$, Human; 1-42, A $\beta_{1-42}$; Peptide Institute, Inc., Osaka, Japan) was incubated for $24 \mathrm{~h}$ at $37^{\circ} \mathrm{C}$ to allow self-aggregation and oligomerization. The primary neurons and astrocytes were incubated with $\mathrm{A} \beta$ (at dosages of $0,3,10$ and $30 \mathrm{nM}$ ) for $24 \mathrm{~h}$ for the following cytotoxicity test. To investigate the protective effects of Dex against $A \beta$ and the underlying mechanisms, the cells were 
simultaneously treated with $\mathrm{A} \beta$ and Dex (Sigma-Aldrich; Merck KGaA), Recombinant Human/Murine/Rat BDNF protein (ab9794) or Trichostatin A (ab120850; both Abcam, Cambridge, UK), a selective inhibitor of HDACs for $24 \mathrm{~h}$.

MTT assay. Neurons and astrocytes were cultured in 96-well plates. MTT solution (Nanjing KeyGEN Biotech, Nanjing, China) was added after the cell treatments. The formazan crystals in cells was dissolved sufficiently after the incubation with dimethylsulfoxide for $4 \mathrm{~h}$ at $37^{\circ} \mathrm{C}$. The absorbance was determined with a Microplate Reader (ELX-800; BioTek Instruments, Inc., Winooski, VT, USA) at $570 \mathrm{~nm}$.

Cell apoptosis assay. Neurons and astrocytes were plated at $2 \times 10^{5}$ cells/well in chamber culture slides and incubated overnight. After the cell treatments, the cells were rinsed with PBS and double-stained with Annexin V-FITC and propidium iodide according to the manufacturer's instruction (Solarbio Science \& Technology Co., Ltd., Beijing, China). The apoptosis rate was determined using a dual laser flow cytometer (Becton Dickinson, San Jose, CA, USA) with the ModFitLT software (Verity Software House, Topsham, ME, USA).

Reverse transcription-quantitative polymerase chain reaction (RT-qPCR) analysis. Total mRNA was extracted from treated neurons and astrocytes using TRIzol reagent following the manufacturer's protocol (Takara, Dalian, China). The mRNA was reverse-transcribed into cDNA using the PrimeScript RT Reagent Kit (Takara). RT-qPCR was performed in the iQ5 Multi-color Real-Time PCR Detection System (Bio-Rad, Hercules, CA, USA) using SYBR Premix Ex Taq II (Takara). The thermocycling conditions were as follows: Initial denaturation at $95^{\circ} \mathrm{C}$ for $10 \mathrm{~min}$, followed by 40 cycles of denaturation at $95^{\circ} \mathrm{C}$ for $15 \mathrm{sec}$, annealing at $60^{\circ} \mathrm{C}$ for $1 \mathrm{~min}$ and extension at $72^{\circ} \mathrm{C}$ for $1 \mathrm{~min}$. The RT-qPCR primer sequences for $B D N F$ and $18 S$ rRNA were as follows: $B D N F$ forward, 5'-AGCTGA GCGTGTGTGACAGT-3' and reverse, 5'-ACCCATGGGATT ACACTTGG-3'; $18 S$ rRNA forward, 5'-GCAATTATTCCC CATGAACG-3' and reverse, 5'-GGCCTCACTAAACCATCC AA-3'. A melting curve analysis of the amplified products was performed at the end of each PCR cycle. The comparative $\mathrm{Cq}$ method (27) was used to quantify the expression of $B D N F$ using $18 S$ rRNA as the normalization control.

Western blot analysis. Neurons and astrocytes were seeded in culture plates at a density of $1 \times 10^{6}$ cells/well. After the cell treatments, the cells were harvested and washed with PBS. Cells were lysed in RIPA buffer (Promega, Madison, WI, USA) containing protease inhibitor cocktail (Roche, Basal, Switzerland). Nuclear protein was extracted using a Nuclear Extract Kit according to the manufacturer's instructions (Active Motif, Carlsbad, CA, USA). The concentrations of total protein in the whole-cell lysate and nuclear protein extracts were determined by the Bradford assay. An equal amount $(20 \mu \mathrm{g})$ of protein in each sample was separated by 10 or $15 \%$ sodium dodecyl sulfate-polyacrylamide gel electrophoresis (SDS-PAGE) and then transferred to a polyvinylidene difluoride membrane (Millipore, Bedford, MA, USA). The membrane was incubated with $5 \%(\mathrm{w} / \mathrm{v})$ skim milk in PBS ( $\mathrm{pH} 7.4)$ containing $0.05 \%$ Tween-20 (PBS-T) at room temperature for $1 \mathrm{~h}$, washed with PBS-T and then probed with anti-BDNF antibody (1:800 dilution; ab108319), anti-GAPDH antibody (1:1,500 dilution; ab9485), anti-HDAC2 antibody (1:1,000 dilution; ab16032), anti-HDAC5 antibody (1:1,000 dilution; ab1439), anti-acetyl-histone H3 antibody (1:800 dilution; ab47915) and anti-histone H2A antibody (1:1,000 dilution; ab88770; all Abcam) for $2 \mathrm{~h}$ at room temperature. The membrane was washed in PBS-T and then incubated with HRP-conjugated goat anti-rabbit IgG secondary antibody (dilution 1:1,500; Santa Cruz Biotechnology, Inc., Santa Cruz, CA, USA) for $1 \mathrm{~h}$ at room temperature. Reactive proteins were detected using Enhanced Chemiluminescent and SuperSignal ${ }^{\mathrm{TM}}$ Chemiluminescent substrates (Pierce, Rockford, IL, USA).

ELISA assay. Cell culture supernatants were collected. BDNF $\operatorname{Emax}^{\circledR}$ ImmunoAssay System kit was used to determine the BDNF concentrations (Promega), according to the manufacturer's instructions. The plates were washed after the reaction with $100 \mu \mathrm{l}$ of o-phenylenediamine substrate (Promega) added to each well. Plates were incubated for $30 \mathrm{~min}$ at room temperature, after which $50 \mu \mathrm{l} /$ well of $4 \mathrm{~N}$ sulfuric acid was added. The microplate reader was used to quantify the absorbance at $490 \mathrm{~nm}$.

Statistical analysis. All data from at least three independent experiments were presented as the mean \pm standard deviation. The statistical analysis was performed using one-way analysis of the variance followed by Dunnett's post hoc test using SPSS version 10.0 software (SPSS, Inc., Chicago, IL, USA). P<0.05 was considered to indicate a statistically significant difference.

\section{Results}

Dex attenuates $A \beta$-induced toxicity in neurons and astrocytes. Primary neurons and astrocytes were respectively isolated from the hippocampus and cerebral cortex tissues of 1-2 days' neonatal Sprague Dawley rats. The staining of $\beta$-Tubulin III and GFAP in ICC assay confirmed the successful isolation of neurons and astrocytes, respectively (Fig. 1A). The exposure of neurons to $10 \mathrm{nM} \mathrm{A} \beta$ resulted in a reduction in the cell viability $(\mathrm{P}<0.05$, Fig. 1B), agreeing to the reported toxicity of $A \beta$ on neurons and astrocytes. The viability of both neurons and astrocytes was attenuated by $30 \mathrm{nM} \mathrm{A} \beta(\mathrm{P}<0.05)$. As shown in Fig. 1C, $0.1 \mu \mathrm{M}$ Dex reversed the reduction of both neuron and astrocyte viability caused by $30 \mathrm{nM} \mathrm{A} \beta(\mathrm{P}<0.05)$. The reversion effect detected under $1 \mu \mathrm{M}$ Dex treatment was stronger compared to $0.1 \mu \mathrm{M}$ Dex treatment $(\mathrm{P}<0.05)$. But no further improvement was observed under $10 \mu \mathrm{M}$ Dex treatment. The pro-apoptotic effect of $\mathrm{A} \beta$ takes the major responsibility for the toxicity. Analysis of flow cytometer showed that $30 \mathrm{nM}$ $\mathrm{A} \beta$ significantly increased the apoptosis rate of neurons and astrocytes at approximate 2.5 -fold $(\mathrm{P}<0.01)$ and 2.2 -fold $(\mathrm{P}<0.05)$ compared to the control, respectively (Fig. 1D). Co-treatment with $1 \mu \mathrm{M}$ Dex and $30 \mathrm{nM} \mathrm{A} \beta$ decreased apoptosis rate of neurons from 64 to $38 \%(\mathrm{P}<0.05)$, and astrocytes from 43 to $27 \%(\mathrm{P}<0.05)$. Although Dex attenuated $\mathrm{A} \beta$-induced toxicity in neurons and astrocytes, the treatment with Dex, alone, at a suitable range of concentrations had no significant effect on viability and apoptosis of neurons and astrocytes (data not shown). 
A

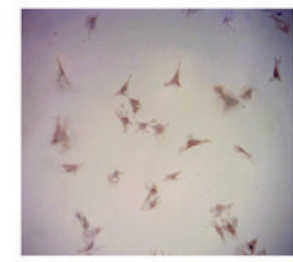

Neurons

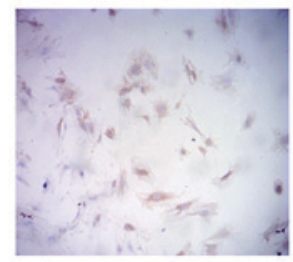

Astrocytes

$(x 400)$

B

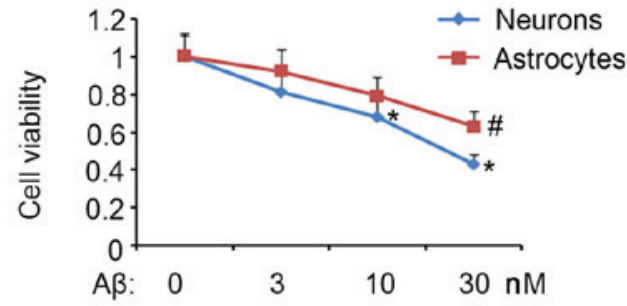

C
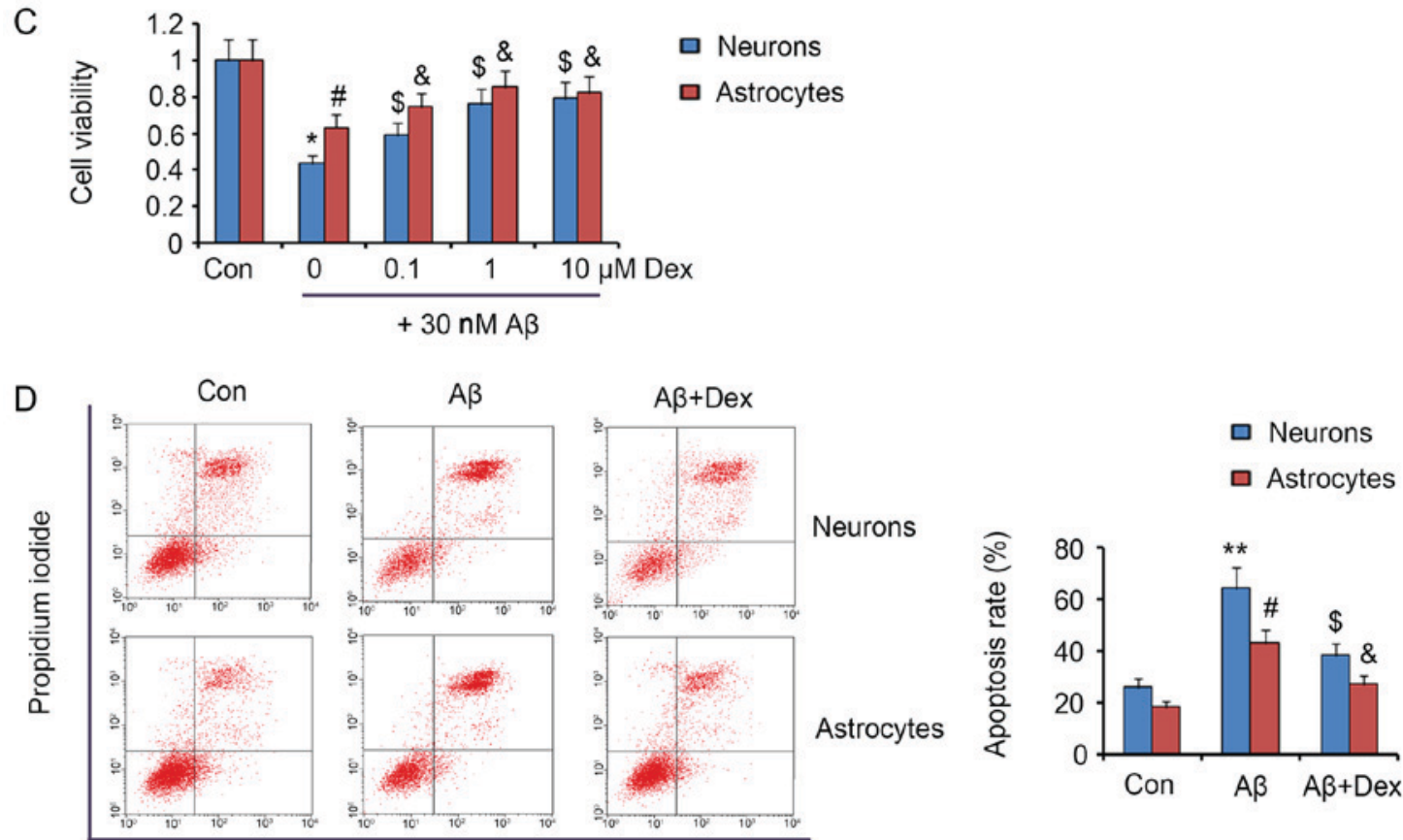

Annexin V FITC

Figure 1. Protection of Dex against A $\beta$-induced toxicity in neurons and astrocytes. (A) Primary neurons and astrocytes were isolated, respectively, from the hippocampus and cerebral cortex of neonatal Sprague Dawley rats. Immunocytochemistry was performed to identify the types and purity of the isolated cells using antibodies targeting $\beta$-Tubulin III and glial fibrillary acidic protein, the specific markers for neurons and astrocytes respectively (magnification, $\mathrm{x} 400$ ). (B) The isolated neurons and astrocytes were incubated with $\mathrm{A} \beta$ for $24 \mathrm{~h}$ prior to cell viability evaluation. " $\mathrm{P}<0.05$ vs. neuron control $(0 \mathrm{nM})$; "P<0.05 vs. astrocyte control $(0 \mathrm{nM})$. (C) Different doses of Dex were added to neurons and astrocytes treated with $30 \mathrm{nM}$ A $\beta$ for cell viability assessment. (D) The isolated neurons and astrocytes were co-treated with $30 \mathrm{nM} \mathrm{A} \beta$ and $10 \mu \mathrm{M}$ Dex, followed by apoptosis assay. " $\mathrm{P}<0.05$ and ${ }^{* *} \mathrm{P}<0.01$ vs. neuron control; ${ }^{*} \mathrm{P}<0.05 \mathrm{vs}$. astrocyte control; ${ }^{\$} \mathrm{P}<0.05$ vs. neuron $\mathrm{A} \beta$ group; ${ }^{\mathrm{P}} \mathrm{P}<0.05$ vs. astrocyte $\mathrm{A} \beta$ group. Dex, dexmedetomidine; $\mathrm{A} \beta, \beta$-Amyloid; FITC, fluorescein isothiocyanate.

Dex inhibits $A \beta$-induced reduction of BDNF in neurons and astrocytes. The importance of BDNF in supporting the proliferation and development of neurons and astrocytes has been established by previous studies. However, $A \beta$ has inhibitory effect on BDNF production. In this study, $30 \mathrm{nM} \mathrm{A} \beta$ decreased $B D N F$ mRNA levels in both neurons and astrocytes $(\mathrm{P}<0.05$, Fig. 2A). However, $1 \mu \mathrm{M}$ Dex inhibited the reduction of $B D N F$ mRNA levels in neurons and astrocytes $(\mathrm{P}<0.05)$ compared to the control. Western blot assay also showed decreased BDNF protein levels in neurons and astrocytes by $\mathrm{A} \beta(\mathrm{P}<0.05$, Fig. $2 \mathrm{~B})$, but Dex rescued the reduction of BDNF protein $(\mathrm{P}<0.05$, Fig. $2 \mathrm{~B})$. It has known that $\mathrm{BDNF}$ expression is notably impacted by the acetylation degree of histone $\mathrm{H} 3$. $\mathrm{A} \beta$ has been reported to promote to HDACs accumulation in cell nucleus. In addition, A $\beta$ increased HDAC 2 and HDAC5 protein levels in the cell nucleus in both neurons and astrocytes $(\mathrm{P}<0.05)$. Consequently, acetylated histone $\mathrm{H} 3$ decreased under $A \beta$ treatment $(P<0.05)$. Dex inhibited the increase of HDAC2 and HDAC5 protein levels in the cell nucleus in neurons under $A \beta$ treatment $(P<0.05$ vs. $A \beta$ group). In astrocytes, Dex only inhibited A $\beta$-induced increase of HDAC2
$(\mathrm{P}<0.05$ vs. $\mathrm{A} \beta$ group). As a result, $\mathrm{A} \beta$-promoted acetylation of histone $\mathrm{H} 3$ in neurons and astrocytes was inhibited by Dex $(\mathrm{P}<0.05$ vs. $\mathrm{A} \beta$ group). Besides, $\mathrm{A} \beta$ decreased BDNF concentrations in neurons and astrocytes $(\mathrm{P}<0.05$; Fig. $2 \mathrm{C})$, which was reversed by Dex treatment $(\mathrm{P}<0.05$; Fig. $2 \mathrm{C})$.

$B D N F$ mediates the protective effect of Dex against $A \beta$. Trichostatin A, a selective inhibitor of HDACs, was added to neurons and astrocytes with Dex and $A \beta$ to further investigate the effect of Dex against $A \beta$-promoted BDNF production by inhibiting HDAC2 and HDAC5. Treatment with $0.2 \mu \mathrm{m}$ Trichostatin A increased $B D N F$ mRNA expression that was reduced by $\mathrm{A} \beta(\mathrm{P}<0.05$ vs. $\mathrm{A} \beta$ group, Fig. $3 \mathrm{~A})$. Moreover, extracellular concentration of BDNF increased by Trichostatin A in $\mathrm{A} \beta$-treated neurons $(\mathrm{P}<0.01$ vs. $\mathrm{A} \beta$ group, Fig. $3 \mathrm{~B})$ and astrocytes $(\mathrm{P}<0.05$ vs. $A \beta$ group). Although our data herein demonstrated that Dex reversed the reduced production of BDNF by $A \beta$, it remained unclear whether the protective effect of Dex against $A \beta$ is associated to BDNF functions. As Trichostatin A could also increase BDNF production and secretion by $\mathrm{A} \beta$-treated neurons and astrocytes, Trichostatin A theoretically has similar 
A

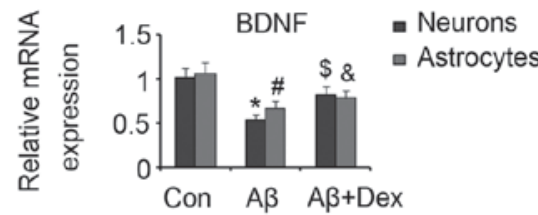

B
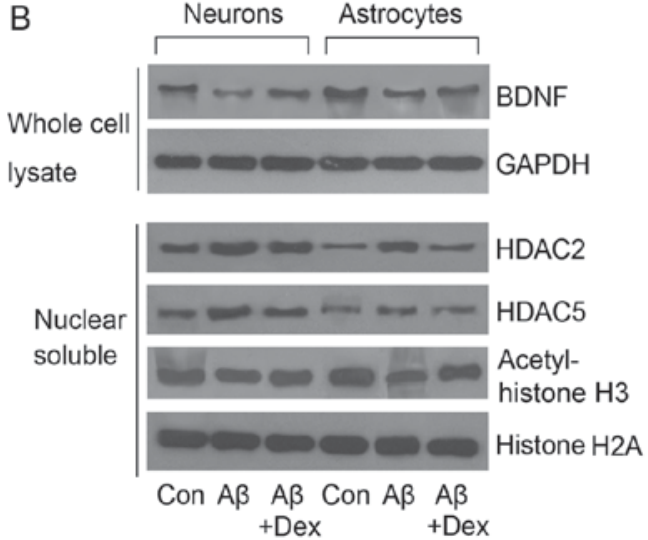

C

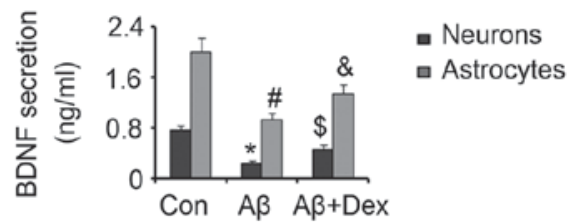

BDNF - Astrocytes
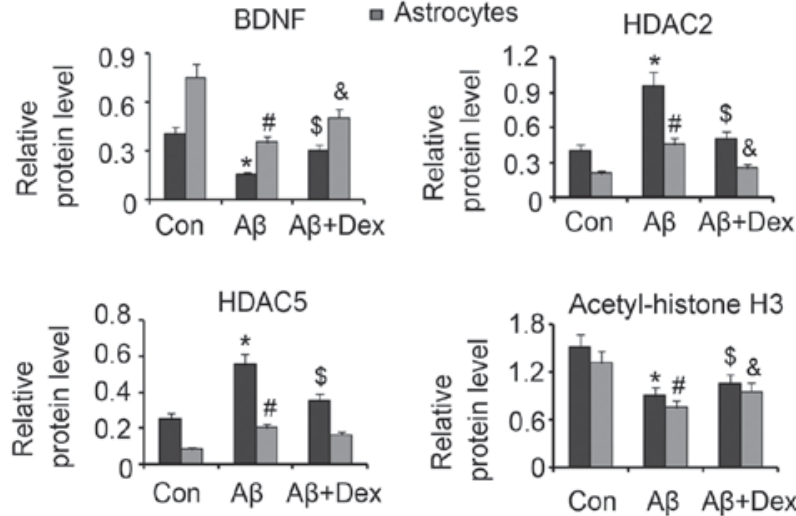

Figure 2. Dex inhibits the effects of $A \beta$ on specific genes and proteins. The neurons and astrocytes were incubated in $30 \mathrm{nM} A \beta$ in the presence or absence of $10 \mu \mathrm{M}$ Dex, followed by the (A) reverse transcription-quantitative polymerase chain reaction, (B) western blotting and (C) ELISA assays to assess the levels of specific genes or proteins. ${ }^{*} \mathrm{P}<0.05$ vs. neuron control; ${ }^{*} \mathrm{P}<0.05$ vs. astrocyte control; ${ }^{~} \mathrm{P}<0.05$ vs. neuron $\mathrm{A} \beta$ group; ${ }^{\text {\& }} \mathrm{P}<0.05$ vs. astrocyte $\mathrm{A} \beta$ group. Dex, dexmedetomidine; $\mathrm{A} \beta, \beta$-Amyloid; BDNF, brain-derived neurotrophic factor; HDAC, histone deacetylase.

A

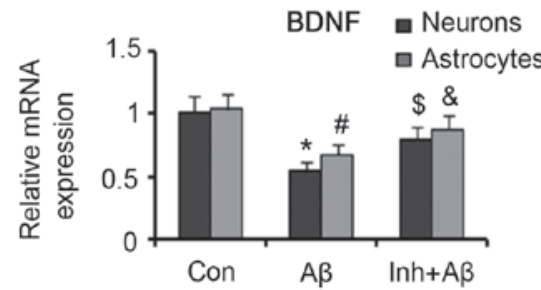

C

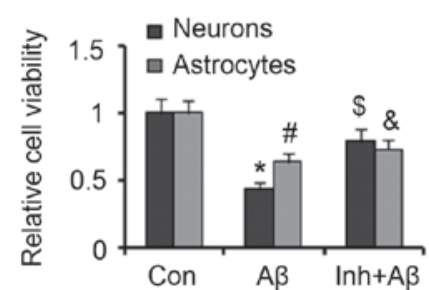

B

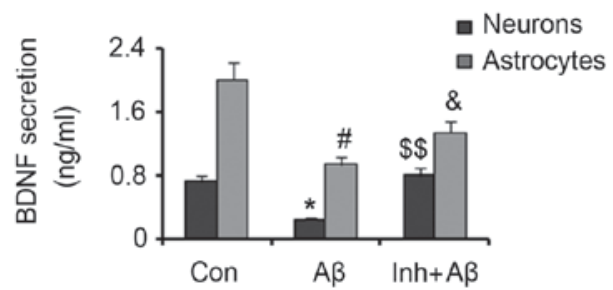

D

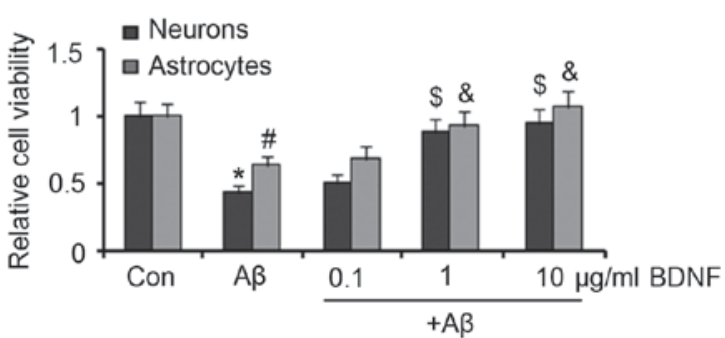

E

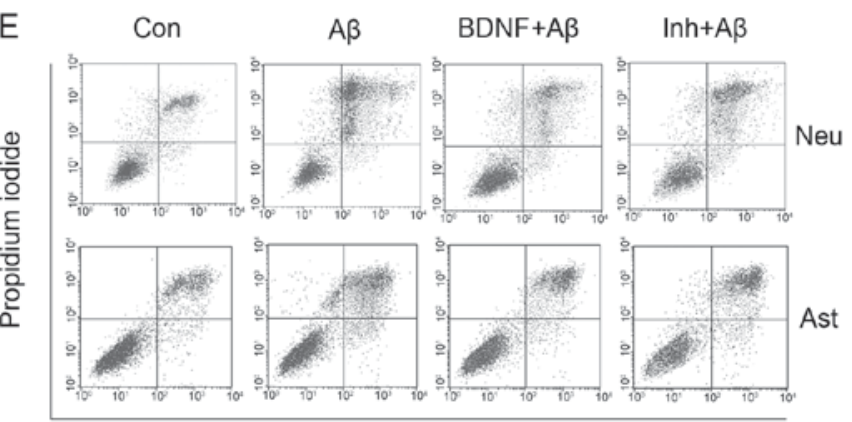

Annexin V FITC

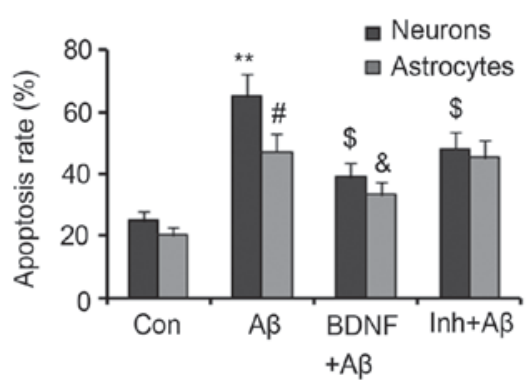

Figure 3. Protective effect of Trichostatin A and recombinant BDNF protein against A $\beta$ in neurons and astrocytes. Trichostatin A was added to neurons and astrocytes treated with $30 \mu \mathrm{M} A \beta$. (A) Reverse transcription-quantitative polymerase chain reaction and (B) ELISA assays detected BDNF mRNA expression and secretion, respectively. (C) Viabilities of the treated neurons and astrocytes were measured. (D) Different doses of recombinant BDNF protein were added to neurons and astrocytes that were treated with $30 \mathrm{nM} \mathrm{A} \beta$. Then the cell viability was assessed. (E) The isolated neurons and astrocytes were incubated with $\mathrm{A} \beta$ alone or in combination with Trichostatin $\mathrm{A}$ or recombinant BDNF protein. Then, the apoptotic rate was assessed by flow cytometry. ${ }^{*}<0.05$ and ${ }^{* *} \mathrm{P}<0.01$ vs. neuron control; ${ }^{\#} \mathrm{P}<0.05$ vs. astrocyte control; ${ }^{\$} \mathrm{P}<0.05$ and ${ }^{\$ \$} \mathrm{P}<0.01$ vs. neuron $\mathrm{A} \beta$ group; ${ }^{\&} \mathrm{P}<0.05$ vs. astrocyte $\mathrm{A} \beta$ group. Dex, dexmedetomidine; A $\beta, \beta$-Amyloid; BDNF, brain-derived neurotrophic factor; HDAC, histone deacetylase; Inh, the inhibitor of HDACs, Trichostatin A; FITC, fluorescein isothiocyanate; Neu, neurons; Ast, astrocytes. 
protective effect with Dex. Co-treatment with Trichostatin A $(0.2 \mu \mathrm{m})$ and $\mathrm{A} \beta(30 \mathrm{~nm})$ increased viabilities of neurons and astrocytes compared with $\mathrm{A} \beta$ treatment alone (both $\mathrm{P}<0.05$; Fig. 3C), suggesting similar protective effect with Dex. In addition, we added recombinant BDNF protein to $\mathrm{A} \beta$-treated neurons and astrocytes, to further verify the role of BDNF in the protection of Dex against $A \beta$. As the biological activity of the recombinant BDNF protein produced by Escherichia coli is lower than that of BDNF secreted from neurons and astrocytes, we added relatively high levels of recombinant BDNF protein in the cell medium. Recombinant BDNF protein at $0.1 \mu \mathrm{m}$ had significantly lower effect on improving viability of neurons and astrocytes ( $\mathrm{P}>0.05$ vs. A $\beta$ group; Fig. 3D). However, 1 and $10 \mu \mathrm{m}$ recombinant BDNF significantly increased viabilities of neurons and astrocytes $(\mathrm{P}<0.05$ vs. $\mathrm{A} \beta$ group). Flow cytometer results showed that $10 \mu \mathrm{m}$ recombinant BDNF significantly lowered apoptosis rates of neurons and astrocytes that was increased by $\mathrm{A} \beta$ ( $\mathrm{P}<0.05$ vs. $\mathrm{A} \beta$ group). Treatment with Trichostatin $\mathrm{A}$ inhibited $A \beta$-induced apoptosis of neurons ( $\mathrm{P}<0.05$ vs. $A \beta$ group), but had no significant effect on apoptosis rate of astrocytes.

\section{Discussion}

$\mathrm{A} \beta$-induced neurotoxicity and neuroinflammation play an important role in $\mathrm{AD}$ pathogenesis. $\mathrm{A} \beta$ causes neuronal cell death in the development of $\mathrm{AD}$, resulting in cognitive and behavioral deficits $(28,29)$. The neuronal cell death is closely related to $\mathrm{A} \beta$-induced oxidative stress and consequent activation of pro-apoptosis signaling, because antioxidative substances and inhibition of apoptosis signaling, alone or in combination, prevent the cell death (30-32). Astrocytes, a major glial cell type in the brain, participate in the neuropathogenic mechanisms after chronic exposure to $\mathrm{A} \beta$ (30). $\mathrm{A} \beta$ can activate astrocytes and then induce the release of inflammatory and neurotoxic molecules, contributing to chronic neuroinflammation and neuronal death (30). It is noteworthy that activated astrocytes have increased levels of the three essential components for $A \beta$ production: amyloid precursor protein, $\beta$-secretase and $\gamma$-secretase, indicating a vicious circle between $\mathrm{A} \beta$ production and astrocyte activation (30). The effect of $A \beta$ on growth performance of astrocytes remains controversial. Some studies report that $A \beta_{1-42}$ is toxic to primary cultures of astrocytes and suppresses the viability $(20,33)$, while no significant effect of $A \beta_{1-42}$ on proliferation of astrocytes was observed by Baglietto-Vargas et al (34). Non-aggregated A $\beta_{25-35}$ even promotes primary astrocyte proliferation in vitro (35). In the present study, $A \beta_{1-42}$ inhibited the viability of both neurons and astrocytes, and contributed to their apoptosis, suggesting the toxicity of $\mathrm{A} \beta_{1-42}$ on both types of cells.

Dex is one of the few anesthetics with neuroprotective property. It has reported that Dex mitigates the LPS-induced neuroinflammation in the hippocampus and cortex by inhibiting the expression of ILI- $\beta$ and $T N F$ - $\alpha$ genes (36). In addition, Dex protects neuronal cells from cerebral ischemia injury (21). The protective mechanisms associate the inhibition of matrix metalloproteinases, caspase-3 activation, DNA fragmentation and cell apoptosis which are induced during cerebral ischemia $(21,36)$. A recent study reported decreased incidence of postoperative cognitive dysfunction in Dex-treated AD patients and aged people (23). As A $\beta$ is the most important causative factor of $\mathrm{AD}$, the present study investigated whether Dex could neutralize the toxicity of $A \beta$. Dex attenuated the inhibitory effect of $A \beta$ on viabilities of neurons and astrocytes and reduced their apoptosis in response to $A \beta$, suggesting the potential protective effect of Dex against AD.

BDNF participates in the regulation of neuronal survival, differentiation and synaptic plasticity as well as influences formation and consolidation of memory $(4,37)$. Treatment with exogenous BDNF or overexpression of BDNF by adenovirus vector shows protective effect against the apoptosis of neurons and astrocytes (38-40). Human and preclinical studies suggest that the loss of BDNF is involved in AD. Inhibited BDNF expression in brain leads to cognitive decline in people with AD and mild cognitive impairment and older adults (41). Application of exogenous BDNF decreased $A \beta$ production in primary neurons by regulating intracellular trafficking and cleavage of amyloid precursor protein (42). Moreover, $\mathrm{BDNF}$ rescued $\mathrm{A} \beta$-mediated neuronal toxicity in animal models, remitting $A \beta$-induced deficits in spatial learning and memory (43). Intriguingly, A $\beta$ can in turn downregulate the expression of BDNF in the brain (44) and block BDNF signaling by impairing axonal transport (45). $A \beta$ at sublethal concentrations interferes with the BDNF-induced activation of the Ras/ERK andPI3K/Akt pathways, resulting increased vulnerability of neurons and inhibited BDNF protection against DNA damage- and trophic deprivation-induced apoptosis (2).

The reduction of BDNF by $\mathrm{A} \beta$ may be relevant to the epigenetic modification. $A \beta$ induces the expression of HDAC2and increases the nuclear translocation of HDACs in human neurons. HDAC2 can bind the promoter region of BDNF exon IV and contribute to the histone $\mathrm{H} 3$ deacetylation, resulting in the suppressed expression of BDNF (14). The regulatory mechanism was also studied by using the selective inhibitor of HDACs to rescue the A $\beta$-induced suppression of BDNF expression and increase the BDNF production. Dex inhibits the expression of HDAC2 and HDAC5 in LPS-stimulated rat renal tubular epithelial NRK52E cells which leads to the septic acute kidney injury (24). However, the effect of Dex on HDAC2 and HDAC5 in neurons and astrocytes has never been reported. In the present study, Dex decreased HDAC2 and HDAC5 accumulation in the cell nucleus in neurons and astrocytes that were subjected to $A \beta$, resulting in an increased acetylation of histone H3. Additionally, Dex inhibited $\mathrm{A} \beta$-induced reduction in BDNF, suggesting that Dex protect cells against $\mathrm{A} \beta$ toxicity by promoting BDNF production. This hypothesis was supported by protective effects from recombinant BDNF protein. The protective effect of many other agents, such as Smilagenin and Aripiprazole, against A $\beta$ is also dependent on $\operatorname{BDNF}(7,46)$. Class I HDAC inhibitors are believed to have positive effects on neurite outgrowth, synaptic plasticity, and neurogenesis in adult brain (47). In previous report, Trichostatin A, a pan-HDAC inhibitor, promoted functional recovery from stroke in mice when used in the delayed phase (48). Trichostatin A increased the production of BDNF and serotonin, and further protected the neuronal cell damage caused by some toxic agents (49-51). Although Trichostatin A also protects neurons and astrocytes by increasing BDNF in the present study, it has some side effects as a pan-inhibitor of HDACs and is limitedly used (11). In the 
present study, Trichostatin A failed to suppress A $\beta$-induced astrocytes' apoptosis, which may explain its side effects on the beneficial functions of BDNF.

In summary, this study provided a novel evidence that Dex can antagonize the toxicity of $\mathrm{A} \beta$ on neurons and astrocytes. It also revealed that the protective mechanism is particularly relevant to the promoted BDNF expression by inhibiting the HDAC2- and HDAC5-induced deacetylation of histone H3. This study laid a foundation for further study of Dex protection against $A \beta$ on neuron and astrocytein animal models and pre-clinical researches.

\section{Acknowledgements}

Not applicable.

\section{Funding}

No funding was received.

\section{Availability of data and materials}

All data generated or analyzed during this study are included in this published article, and are also available from the corresponding author on reasonable request.

\section{Authors' contributions}

WM conceived and designed the study. YW and AJ performed the experiments and wrote the manuscript. All authors have read and approved the final manuscript.

\section{Ethics approval and consent to participate}

The present study was approved by the Ethics Committee of Xiangya School of Medicine.

\section{Patient consent for publication}

Not applicable.

\section{Competing interests}

The authors declare that they have no competing interests.

\section{References}

1. Kazim SF and Iqbal K: Neurotrophic factor small-molecule mimetics mediated neuroregeneration and synaptic repair: Emerging therapeutic modality for Alzheimer's disease. Mol Neurodegener 11: 50, 2016.

2. Tong L, Balazs R, Thornton PL and Cotman CW: Beta-amyloid peptide at sublethal concentrations downregulates brain-derived neurotrophic factor functions in cultured cortical neurons. J Neurosci 24: 6799-6809, 2004.

3. Frost GR and Li YM: The role of astrocytes in amyloid production and Alzheimer's disease. Open Biol 7: pii: 170228, 2017.

4. Benussi L, Binetti G and Ghidoni R: Loss of neuroprotective factors in neurodegenerative dementias: The end or the starting point? Front Neurosci 11: 672, 2017.

5. Peng S, Wuu J, Mufson EJ and Fahnestock M: Precursor form of brain-derived neurotrophic factor and mature brain-derived neurotrophic factor are decreased in the pre-clinical stages of Alzheimer's disease. J Neurochem 93: 1412-1421, 2005.
6. Buchman AS, Yu L, Boyle PA, Schneider JA, De Jager PL and Bennett DA: Higher brain BDNF gene expression is associated with slower cognitive decline in older adults. Neurology 86: 735-741, 2016.

7. Park SY, Shin HK, Lee WS, Bae SS, Kim K, Hong KW and Kim CD: Neuroprotection by aripiprazole against $\beta$-amyloid-induced toxicity by P-CK $2 \alpha$ activation via inhibition of GSK-3ß. Oncotarget 8: 110380-110391, 2017.

8. Arancibia S, Silhol M, Moulière F, Meffre J, Höllinger I, Maurice T and Tapia-Arancibia L: Protective effect of BDNF against beta-amyloid induced neurotoxicity in vitro and in vivo in rats. Neurobiol Dis 31: 316-326, 2008.

9. Zhang L, Fang Y, Lian Y, Chen Y, Wu T, Zheng Y, Zong H, Sun L, Zhang R, Wang $\mathrm{Z}$ and $\mathrm{Xu} \mathrm{Y}$ : Brain-derived neurotrophic factor ameliorates learning deficits in a rat model of Alzheimer's disease induced by aß1-42. PLoS One 10: e0122415, 2015.

10. Yang XJ and Seto E: Lysine acetylation: Codified crosstalk with other posttranslational modifications. Mol Cell 31: 449-461, 2008.

11. Zhu X, Wang S, Yu L, Jin J, Ye X, Liu Y and Xu Y: HDAC3 negatively regulates spatial memory in a mouse model of Alzheimer's disease. Aging Cell 16: 1073-1082, 2017.

12. Sen A, Nelson TJ and Alkon DL: ApoE4 and A $\beta$ oligomers reduce BDNF expression via HDAC nuclear translocation. J Neurosci 35: 7538-7551, 2015.

13. Tang $\mathbf{J}$ and Zhuang S: Epigenetics in acute kidney injury. Curr Opin Nephrol Hypertens 24: 351-358, 2015.

14. Wang BY, Zhong Y, Zhao Z and Miao Y: Epigenetic suppression of hippocampal BDNF mediates the memory deficiency induced by amyloid fibrils. Pharmacol Biochem Behav 126: 83-89, 2014.

15. Xie Z, Dong Y, Maeda U, Alfille P, Culley DJ, Crosby G and Tanzi RE: The common inhalation anesthetic isoflurane induces apoptosis and increases amyloid beta protein levels. Anesthesiology 104: 988-994, 2006.

16. Zhang S, Hu X, Guan W, Luan L, Li B, Tang Q and Fan H: Isoflurane anesthesia promotes cognitive impairment by inducing expression of $\beta$-amyloid protein-related factors in the hippocampus of aged rats. PLoS One 12: e0175654, 2017.

17. Evered L, Scott DA and Silbert B: Cognitive decline associated with anesthesia and surgery in the elderly: Does this contribute to dementia prevalence? Curr Opin Psychiatry 30: 220-226, 2017

18. Bilotta F, Qeva E and Matot I: Anesthesia and cognitive disorders: A systematic review of the clinical evidence. Expert Rev Neurother 16: 1311-1320, 2016.

19. Wu J, Bie B and Naguib M: Epigenetic manipulation of brain-derived neurotrophic factor improves memory deficiency induced by neonatal anesthesia in rats. Anesthesiology 124: 624-640, 2016.

20. Ryu YK, Khan S, Smith SC and Mintz CD: Isoflurane impairs the capacity of astrocytes to support neuronal development in a mouse dissociated coculture model. J Neurosurg Anesthesiol 26: 363-368, 2014.

21. Liu YJ, Wang DY, Yang YJ and Lei WF: Effects and mechanism of dexmedetomidine on neuronal cell injury induced by hypoxia-ischemia. BMC Anesthesiol 17: 117, 2017.

22. Shen $M$, Wang $S$, Wen $X$, Han XR, Wang YJ, Zhou XM, Zhang MH, Wu DM, Lu J and Zheng YL: Dexmedetomidine exerts neuroprotective effect via the activation of the $\mathrm{PI} 3 \mathrm{~K} / \mathrm{Akt} / \mathrm{mTOR}$ signaling pathway in rats with traumatic brain injury. Biomed Pharmacother 95: 885-893, 2017.

23. Zhou C, Zhu Y, Liu Z and Ruan L: Effect of dexmedetomidine on postoperative cognitive dysfunction in elderly patients after general anaesthesia: A meta-analysis. J Int Med Res 44: 1182-1190, 2016.

24. Hsing CH, Lin CF, So E, Sun DP, Chen TC, Li CF and Yeh CH: $\alpha 2$-Adrenoceptor agonist dexmedetomidine protects septic acute kidney injury through increasing BMP-7 and inhibiting HDAC2 and HDAC5. Am J Physiol Renal Physiol 303: F1443-F1453, 2012.

25. Dong D, Mao Y, Huang C, Jiao Q, Pan H, Ma L and Wang R: Astrocytes mediated the nootropic and neurotrophic effects of Sarsasapogenin-AA13 via upregulating brain-derived neurotrophic factor. Am J Transl Res 9: 4015-4025, 2017.

26. Institute for laboratory animal research: Guide for the care and use of laboratory animals, 8th edition Washington (DC): National Academies Press, 2011.

27. Livak KJ and Schmittgen TD: Analysis of relative gene expression data using real-time quantitative PCR and the 2(-Delta Delta C(T)) method. Methods 25: 402-408, 2001. 
28. Koseoglu MM, Ozdilek BA, Djakbarova U and Gulusur A: Targeting ras activity prevented amyloid beta-induced aberrant neuronal cell cycle re-entry and death. Curr Alzheimer Res 13: $1267-1276,2016$

29. Suganthy N, Malar DS and Devi KP: Rhizophora mucronata attenuates beta-amyloid induced cognitive dysfunction, oxidative stress and cholinergic deficit in Alzheimer's disease animal model. Metab Brain Dis 31: 937-949, 2016.

30. Hettiarachchi NT, Boyle JP, Dallas ML, Al-Owais MM, Scragg JL and Peers C: Heme oxygenase-1 derived carbon monoxide suppresses A $\beta 1-42$ toxicity in astrocytes. Cell Death Dis 8: e2884, 2017.

31. Chay KO, Nam Koong KY, Hwang S, Kim JK and Bae CS: NADPH oxidase mediates $\beta$-amyloid peptide-induced neuronal death in mouse cortical cultures. Chonnam Med J 53: 196-202, 2017.

32. Oguchi T, Ono R, Tsuji M, Shozawa H, Somei M, Inagaki M, Mori Y, Yasumoto T, Ono K and Kiuchi Y: Cilostazol suppresses $\mathrm{A} \beta$-induced neurotoxicity in SH-SY5Y cells through inhibition of oxidative stress and MAPK signaling pathway. Front Aging Neurosci 9: 337, 2017.

33. Aguirre-Rueda D, Guerra-Ojeda S, Aldasoro M, Iradi A Obrador E, Mauricio MD, Vila JM, Marchio P and Valles SL: WIN 55,212-2, agonist of cannabinoid receptors, prevents amyloid $\beta 1-42$ effects on astrocytes in primary culture. PLoS One 10: e0122843, 2015.

34. Baglietto-Vargas D, Sánchez-Mejias E, Navarro V, Jimenez S, Trujillo-Estrada L, Gómez-Arboledas A, Sánchez-Mico M, Sánchez-Varo R, Vizuete M, Dávila JC, et al: Dual roles of A $\beta$ in proliferative processes in an amyloidogenic model of Alzheimer's disease. Sci Rep 7: 10085, 2017.

35. Ohki EC, Langan TJ, Rodgers KR and Chou RC: Non-aggregated A $325-35$ upregulates primary astrocyte proliferation in vitro. Front Cell Neurosci 11: 301, 2017.

36. Yamanaka D, Kawano T, Nishigaki A, Aoyama B, Tateiwa H, Shigematsu-Locatelli M, Locatelli FM and Yokoyama M: Preventive effects of dexmedetomidine on the development of cognitive dysfunction following systemic inflammation in aged rats. J Anesth 31: 25-35, 2017.

37. Chen SD, Wu CL, Hwang WC and Yang DI: More Insight into BDNF against Neurodegeneration: Anti-apoptosis, anti-oxidation, and suppression of autophagy. Int J Mol Sci 18: pii: E545, 2017.

38. Uchida K, Nakajima H, Hirai T, Yayama T, Chen K, Guerrero AR, Johnson WE and Baba $\mathrm{H}$ : The retrograde delivery of adenovirus vector carrying the gene for brain-derived neurotrophic factor protects neurons and oligodendrocytes from apoptosis in the chronically compressed spinal cord of twy/twy mice. Spine (Phila Pa 1976) 37: 2125-2135, 2012.

39. Schizas N, König N, Andersson B, Vasylovska S, Hoeber J, Kozlova EN and Hailer NP: Neural crest stem cells protect spinal cord neurons from excitotoxic damage and inhibit glial activation by secretion of brain-derived neurotrophic factor. Cell Tissue Res 372: 493-505, 2018.
40. Spagnuolo MS, Donizetti A, Iannotta L, Aliperti V, Cupidi C, Bruni AC and Cigliano L: Brain-derived neurotrophic factor modulates cholesterol homeostasis and Apolipoprotein $\mathrm{E}$ synthesis in human cell models of astrocytes and neurons. J Cell Physiol, 11 Jan 2018 (Epub ahead of print).

41. Tapia-Arancibia L, Aliaga E, Silhol M and Arancibia S: New insights into brain BDNF function in normal aging and Alzheimer disease. Brain Res Rev 59: 201-220, 2008.

42. Rohe M, Synowitz M, Glass R, Paul SM, Nykjaer A and Willnow TE: Brain-derived neurotrophic factor reduces amyloidogenic processing through control of SORLA gene expression. J Neurosci 29: 15472-15478, 2009.

43. Arancibia S, Silhol M, Mouliere F, Meffre J, Höllinger I, Maurice T and Tapia-Arancibia L: Protective effect of BDNF against beta-amyloid induced neurotoxicity in vitro and in vivo in rats. Neurobiol Dis 31: 316-326, 2008.

44. Peng S, Garzon DJ, Marchese M, Klein W, Ginsberg SD, Francis BM, Mount HT, Mufson EJ, Salehi A and Fahnestock M: Decreased brain-derived neurotrophic factor depends on amyloid aggregation state in transgenic mouse models of Alzheimer's disease. J Neurosci 29: 9321-9329, 2009.

45. Poon WW, Blurton-Jones M, Tu CH, Feinberg LM, Chabrier MA, Harris JW, Jeon NL and Cotman CW: $\beta$-Amyloid impairs axonal BDNF retrograde trafficking. Neurobiol Aging 32: 821-833, 2011.

46. Zhang R, Wang Z, Howson PA, Xia Z, Zhou S, Wu E, Xia Z and $\mathrm{Hu}$ Y: Smilagenin attenuates beta amyloid (25-35)-induced degeneration of neuronal cells via stimulating the gene expression of brain-derived neurotrophic factor. Neuroscience 210 275-285, 2012.

47. Takamatsu G, Katagiri C, Tomoyuki T, Shimizu-Okabe C, Nakamura W, Nakamura-Higa M, Hayakawa T, Wakabayashi S, Kondo T, Takayama C and Matsushita M: Tescalcin is a potential target of class I histone deacetylase inhibitors in neurons. Biochem Biophys Res Commun 482: 1327-1333, 2017.

48. Tang Y, Lin YH, Ni HY, Dong J, Yuan HJ, Zhang Y, Liang HY, Yao MC, Zhou QG, Wu HY, et al: Inhibiting histone deacetylase 2 (HDAC2) promotes functional recovery from stroke. J Am Heart Assoc 6: pii: e007236, 2017.

49. Fukui T, Asakura K, Hikichi C, Ishikawa T, Murai R, Hirota S, Murate K, Kizawa M, Ueda A, Ito S and Mutoh T: Histone deacetylase inhibitor attenuates neurotoxicity of clioquinol in PC12 cells. Toxicology 331: 112-118, 2015.

50. Asaoka N, Nagayasu K, Nishitani N, Yamashiro M, Shirakawa H, Nakagawa T and Kaneko S: Inhibition of histone deacetylases enhances the function of serotoninergic neurons in organotypic raphe slice cultures. Neurosci Lett 593: 72-77, 2015.

51. Suo H, Wang P, Tong J, Cai L, Liu J, Huang D, Huang L, Wang Z, Huang Y, Xu J, et al: NRSF is an essential mediator for the neuroprotection of trichostatin A in the MPTP mouse model of Parkinson's disease. Neuropharmacology 99: 67-78, 2015. 